\title{
Long-Term Survival of AIDS Patients Treated with Only Traditional Chinese Medicine
}

\author{
Yifei Wang, ${ }^{1}$ Fujun Jin, ${ }^{1}$ Qiaoli Wang, ${ }^{1}$ and Zucai Suo ${ }^{2}$
}

\begin{abstract}
Traditional Chinese herbal medicine (TCM) has been used in Chinese society for more than 5,000 years to treat diseases from inflammation to cancer. Here, we report the case of nine living AIDS patients in the age range of 51 to 67 who were treated with either a unique formula of TCM alone from 2001 to 2009 or the TCM from 2001 to 2006 and then switched to occasional antiretroviral therapy. Surprisingly, the viral loads of eight patients were at undetectable levels on June 28, 2016, while the remaining patient had a low viral load of 29 copies $/ \mathrm{ml}$. The $\mathrm{CD}^{+}$counts $(170-592$ cells $/ \mu \mathrm{l})$ and $\mathrm{CD}^{+} / \mathrm{CD}^{+}$ratios $(0.21-0.90)$ of the nine patients are excellent, contributing to their current good health. Thus, the case study suggests that the TCM has the potential to become a functional cure for HIV/AIDS.
\end{abstract}

Keywords: traditional Chinese herbal medicine, antiretroviral therapy, HIV-1, AIDS, functional cure for HIV/AIDS

A NTIRETROVIRAL THERAPY (ART), a combination of three or more small molecule inhibitors, has been widely used to treat HIV/AIDS patients since the 1990s. Although highly effective, ART is known to cause severe and long-term side effects to patients. Interestingly, some of the side effects associated with ART can be reduced by traditional Chinese herbal medicine (TCM). ${ }^{1}$ TCM also enhances patients' immune functions and reduces AIDS symptoms. ${ }^{1}$ However, there are no reports on long-term survival of AIDS patients treated with only TCM. Here, we report a case series of nine living AIDS patients in the age range of 51 to 67 (Table 1) who have been infected with HIV-1 for 21 to 23 years and were treated with either a unique formula of TCM alone or the TCM for several years before switching to occasional ART. The TCM contains combined extracts from 13 different plants, including Astragalus, Skullcap, and Ginseng (Experiment Methods in Supplementary Data; Supplementary Data are available online at www.liebertpub.com/aid). Through HPLC-based fractionation and drug screening methods, others have previously discovered that some of these plants contain polysaccharides, protein components, alkaloids, lactones, and terpenes, which directly inhibit the enzymatic activities of recombinant HIV-1 protease, reverse transcriptase, and integrase, as well as the interaction between HIV-1 gp120 and immobilized CD4 receptors. ${ }^{1,2}$ The TCM also contains known natural products, which boost the immune system, cytokine stimulation, or other pathways in patients. ${ }^{1,2}$ For example, shikonin can decrease CCR5 mRNA and the expression of CCR5, a chemokine receptor commonly utilized by HIV to enter host immunological cells. ${ }^{2}$

The case series of the TCM was administered by a small Chinese company, which bankrupted by the end of 2009. The enrolled patients, who are poor peasants from an "AIDS Village" in Anhui Province, China, contracted HIV-1 sometime between 1993 and 1995 through commercial plasma donation $^{3}$ and were officially diagnosed at Guangzhou Center for Disease Control and Prevention (Guangzhou, China) on December 19, 2002. At that time, there were at least $42 \mathrm{HIV}$-infected people in the same village but few believed that the TCM could effectively treat AIDS. Accordingly, only nine patients were willing to participate in the case series. By late 2001, all of the nine randomly selected patients showed typical AIDS symptoms after being infected by HIV-1 for 6 to 8 years (Supplementary Table S1), indicating that they are not "long-term nonprogressors." 4,5 For treatment, Patients A-D took the TCM twice daily from 2001

\footnotetext{
${ }^{1}$ Institute of Biomedicine, College of Life Science and Technology, Jinan University, Guangdong, Guangzhou, China.

${ }^{2}$ Department of Chemistry and Biochemistry, Public Health Preparedness for Infectious Diseases Program, and Comprehensive Cancer Center, The Ohio State University, Columbus, Ohio.

(C) Yifei Wang, et al., 2017; Published by Mary Ann Liebert, Inc. This Open Access article is distributed under the terms of the Creative Commons Attribution Noncommercial License (http://creativecommons.org/licenses/by-nc/4.0/) which permits any noncommercial use, distribution, and reproduction in any medium, provided the original author(s) and the source are credited.
} 
Table 1. Viral Loads of the Patients Determined at Different Times And Their $\mathrm{CD}^{+}{ }^{+}$And $\mathrm{CD}^{+}$Counts Measured on June 28, 2016

\begin{tabular}{|c|c|c|c|c|c|c|c|c|c|c|}
\hline \multirow[b]{2}{*}{ Patient } & \multirow[b]{2}{*}{ Gender } & \multirow[b]{2}{*}{ Age } & \multicolumn{5}{|c|}{ Viral load (copies/ml) } & \multirow{2}{*}{$\begin{array}{c}\text { CD4 }^{+} \\
\text {June } 28 \\
2016(\text { cells } / \mu l)\end{array}$} & \multirow{2}{*}{ 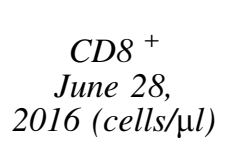 } & \multirow{2}{*}{$\begin{array}{l}C D 4^{+} / C D 8^{+} \\
\text {June } 28, \\
2016\end{array}$} \\
\hline & & & $\begin{array}{c}\text { June 24, } \\
2003\end{array}$ & $\begin{array}{c}\text { September } \\
9,2003\end{array}$ & $\begin{array}{c}\text { September } \\
19,2005\end{array}$ & $\begin{array}{c}\text { June } 24, \\
2006\end{array}$ & $\begin{array}{c}\text { June } 28, \\
2016\end{array}$ & & & \\
\hline A & M & 66 & 96,052 & ND & 9,991 & ND & $<20$ & 375 & 617 & 0.61 \\
\hline B & M & 63 & ND & 2,358 & ND & 57 & $<20$ & 592 & 791 & 0.75 \\
\hline $\mathrm{C}$ & F & 67 & 1,821 & ND & 57 & ND & $<20$ & 447 & 606 & 0.74 \\
\hline $\mathrm{D}$ & $\mathrm{F}$ & 64 & 5,247 & ND & $<50$ & ND & $<20$ & 313 & 842 & 0.37 \\
\hline E & M & 55 & 2,633 & ND & 160 & ND & 29 & 194 & 809 & 0.24 \\
\hline $\mathrm{F}$ & M & 52 & ND & 14,017 & 3,882 & ND & $<20$ & 312 & 1,501 & 0.21 \\
\hline G & $\mathrm{F}$ & 54 & 27,048 & ND & 4,682 & ND & $<20$ & 360 & 398 & 0.90 \\
\hline $\mathrm{H}$ & $\mathrm{F}$ & 51 & ND & 15,060 & 528 & ND & $<20$ & 380 & 1,051 & 0.36 \\
\hline I & $\mathrm{F}$ & 61 & ND & 365,907 & ND & 28,123 & $<20$ & 170 & 256 & 0.66 \\
\hline
\end{tabular}

F, female; M, male; ND, not determined.

to 2009, while Patients E-I took the TCM from 2001 or 2002 to 2006 and then occasionally took some form of ART without TCM from 2007 to 2016 (Supplementary Table S1). Interestingly, AIDS symptoms in all patients were improved after 3 months of the TCM treatment, and almost disappeared after 1 year of the TCM treatment (Supplementary Table S1). The TCM treatment was well tolerated by all patients and displayed little clinical toxicity. While most medical data collected in the case series were unfortunately lost due to the bankruptcy of the company, several recovered plasma viral loads measured from 2003 to 2006 showed significant decreases and varied from patient to patient (Table 1 and Supplementary Figs. S1 and S2). Table 1 also shows that only Patient $C$ had a viral load of slightly lower than 2,000 copies/ $\mathrm{ml}$ on July 24, 2003 after treatment with the TCM for 22 months. It is likely that all nine patients had much higher viral loads than 2,000 copies/ml before they were on the TCM. This disqualifies them from being considered as rare "viremic controllers," who are defined as having viral loads less than 2,000 copies/ml over time with a low prevalence rate of $3.34 \%$ in HIV-infected patients. ${ }^{5}$ Unexpectedly, the viral loads of eight patients were at undetectable levels as measured through COBAS AmpliPrep/TaqMan96 of Roche Molecular Systems (detection limit: 20 copies/ml) on June 28, 2016, while Patient E had a nearly undetectable viral load of 29 copies/ml (Table 1). Furthermore, CD4 ${ }^{+}$ counts $(170-592$ cells $/ \mu \mathrm{l})$ and $\mathrm{CD}^{+} / \mathrm{CD}^{+}$ratios $(0.21-$ 0.90) of the patients (Table 1 and Supplementary Fig. S3) are promising, although below the ranges for uninfected healthy adults. ${ }^{6,7}$ In comparison, a randomized clinical trial with ART on 898 US patients (ACTG 384) showed that the median $\mathrm{CD}^{+}$count increased from 270 cells $/ \mathrm{ml}$ pre-ART to an estimated 532 cells $/ \mathrm{ml}$ seven years after starting ART in analyses ignoring treatment discontinuations. ${ }^{8}$ Consistent with our findings, that clinical trial (ACTG 384) also revealed that a substantial percentage of the patients starting ART at low $\mathrm{CD} 4^{+}$counts still had low $\mathrm{CD} 4^{+}$counts after 7 years on ART. ${ }^{8}$ Taken together, the optimistic T cell parameters and, more importantly, the extremely low viral loads presented in this case series study (Table 1) collectively contribute to the present good health of all patients who are currently carrying out arduous agricultural work. Strikingly, Patients A-D, who have never taken ART and were on the TCM from 2001 to 2009 have not been on any medical treatment since 2010 (Supplementary Table S1), yet, survived more than 15 years after AIDS onset. In contrast, without medical treatment, $82 \%$ of 294,662 patients in a published meta-analysis progressed from AIDS onset to AIDS-related deaths within 6 years. ${ }^{6}$ Consistently, more than $30 \mathrm{HIV}$-infected patients in the same "AIDS Village" as Patients A-D died from AIDS between 1999 and 2003. Notably, none of these deceased patients took the TCM or any form of ART, which were inaccessible to poor Chinese peasants at that time.

However, unlike randomized controlled clinical trials, there was not a control patient group who took a proper placebo during this case series. In addition, the case series has a small sample size and eight of the nine enrolled patients are married couples. The TCM was neither randomly administered nor quantitatively monitored.

The case series data presented here, although incomplete and uncontrolled, demonstrate the promise of the TCM. Therefore, the TCM merits further and more rigorous evaluation through biochemical and biological studies, animal model testing, and randomized controlled clinical trials. ${ }^{1}$ It would also be important to monitor the ART levels in the control group and patient cohorts to verify patient compliance of therapeutic regimens during future clinical investigation. If validated through these rigorous tests, the TCM can be utilized as a cost-effective HIV/AIDS treatment alone or in combination with ART, potentially contributing to a strategy for functional cure.

\section{Acknowledgments}

This work was supported by the National Natural Science Foundation of China (grants 81274170 and 81573471) and the International Cooperation Project of Guangdong Province (grant 2015A050502028) to Y.W., and the discretionary fund from The Ohio State University to Z.S.

\section{Authors' Contributions}

Y.W. and Z.S. designed the project. Y.W. and Q.W. collected the data. Y.W., F.J., and Z.S. analyzed the data. Z.S. wrote the manuscript. Z.S., F.J., and Y.W. edited the manuscript. 


\section{Ethics Committee Approval}

The authors received approval from the Ethics Committee at Jinan University.

\section{Author Disclosure Statement}

No competing financial interests exist.

\section{References}

1. Zou W, Wang J, Liu Y: Effect of traditional Chinese medicine for treating human immunodeficiency virus infections and acquired immune deficiency syndrome: Boosting immune and alleviating symptoms. Chin J Integr Med 2016;22: 3-8.

2. Wang J, Zou W: Practices, challenges, and opportunities: HIV/ AIDS treatment with traditional Chinese medicine in China. Front Med 2011;5:123-126.

3. Wu Z, Liu Z, Detels R: HIV-1 infection in commercial plasma donors in China. Lancet 1995;346:61-62.

4. Madec Y, Boufassa F, Avettand-Fenoel V, Hendou S, Melard A, Boucherit S, et al.: Early control of HIV-1 infection in long-term nonprogressors followed since diagnosis in the ANRS SEROCO/HEMOCO cohort. J Acquir Immune Defic Syndr 2009;50:19-26.

5. Okulicz JF, Marconi VC, Landrum ML, Wegner S, Weintrob A, Ganesan A, et al.: Clinical outcomes of elite controllers, viremic controllers, and long-term nonprogressors in the US Department of Defense HIV natural history study. J Infect Dis 2009;200:1714-1723.

6. Poorolajal J, Hooshmand E, Mahjub H, Esmailnasab N, Jenabi E.: Survival rate of AIDS disease and mortality in HIVinfected patients: A meta-analysis. Public Health 2016;139: $3-12$.

7. Lu W, Mehraj V, Vyboh K, Cao W, Li T, Routy JP.: CD4:CD8 ratio as a frontier marker for clinical outcome, immune dysfunction and viral reservoir size in virologically suppressed HIV-positive patients. J Int AIDS Soc 2015;18: 20052.

8. Lok JJ, Bosch RJ, Benson CA, Collier AC, Robbins GK, Shafer RW, et al.: Long-term increase in CD4+ T-cell counts during combination antiretroviral therapy for HIV-1 infection. AIDS 2010;24:1867-1876.

Address correspondence to: Zucai Suo Department of Chemistry and Biochemistry, Public Health Preparedness for Infectious Diseases Program, and Comprehensive Cancer Center The Ohio State University Columbus, $\mathrm{OH} 43210$

E-mail: suo.3@osu.edu 